\title{
Resistance to powdery mildew in Spanish barley landraces is controlled by different sets of quantitative trait loci
}

Silvar $\mathrm{C}^{1,6}$, Casas $\mathrm{AM}^{1}$, Igartua $\mathrm{E}^{1}$, Ponce-Molina LJ ${ }^{1,7}$, Gracia MP ${ }^{1}$, Schweizer $\mathrm{G}^{2}$, Herz $\mathrm{M}^{2}$, Flath $\mathrm{K}^{3}$, Waugh $\mathrm{R}^{4}$, Kopahnke $\mathrm{D}^{5}$, Ordon $\mathrm{F}^{5}$.

${ }^{1}$ Department of Genetics and Plant Production, Aula Dei Experimental Station, EEAD-CSIC, Avda Montañana 1005, 50059-Zaragoza, Spain

${ }^{2}$ Institute for Crop Science and Plant Breeding, Bavarian State Research Centre for Agriculture, Am Gereuth 6, D-85354 Freising-Weihenstephan, Germany

${ }^{3}$ Institute for Plant Protection in Field Crops and Grassland, Julius Kühn-Institute, D-14532

Kleinmachnow, Germany

${ }^{4}$ The James Hutton Institute, Invergowrie, DD2 5NE Dundee, Scotland.

${ }^{5}$ Institute for Resistance Research and Stress Tolerance, Julius Kühn Institute (JKI), Federal Research Institute for Cultivated Plants, Erwin-Baur-Str. 27, 06484 Quedlinburg, Germany

${ }^{6}$ Current address: Department of Ecology, Plant and Animal Biology, University of Coruña, Campus da Zapateira s/n, E-15071 A Coruña, Spain.

${ }^{7}$ Current address: National Autonomous Institute for Agricultural Research (INIAP), Santa Catalina Experimental Station, Panamericana Sur Km1, Quito, Ecuador

\footnotetext{
* Corresponding autor: Ernesto Igartua
}

Phone: +34 976716083

Fax: +34976 716145

Email: igartua@eead.csic.es 


\section{Abstract}

Twenty-two landrace-derived inbred lines from the Spanish Barley Core Collection (SBCC) were found to display high levels of resistance to a panel of 27 isolates of the fungus Blumeria graminis that exhibit a wide variety of virulences. Among these lines, SBCC145 showed high overall resistance and a distinctive spectrum of resistance compared with the other lines. Against this background, the main goal of the present work was to investigate the genetic basis underlying such resistance using a doubled haploid population derived from a cross between SBCC145 and the elite spring cultivar Beatrix. The population was genotyped with the 1,536-SNP Illumina GoldenGate Oligonucleotide Pool Assay (Barley OPA-1 or BOPA1 for short), whereas phenotypic analysis was performed using two B. graminis isolates. A major quantitative trait locus (QTL) for resistance to both isolates was identified on the long arm of chromosome $6 \mathrm{H}(6 \mathrm{HL})$, and accounted for ca. $60 \%$ of the phenotypic variance. Depending on the B. graminis isolate tested, three other minor QTLs were detected on chromosomes $2 \mathrm{H}$ and $7 \mathrm{H}$, which explained less than $5 \%$ of the phenotypic variation each. In all cases, the alleles for resistance derived from the Spanish parent SBCC145. The position, the magnitude of the effect observed, and the proportion of phenotypic variation accounted for by the QTL on 6HL suggest this is a newly identified locus for broad-based resistance to powdery mildew.

Keywords: barley, powdery mildew, disease resistance, quantitative trait locus, landrace 


\section{Introduction}

The most effective method of disease control in sustainable cropping systems is the use of resistant cultivars. However, this strategy depends on the continuous supply of new sources of resistance to overcome the challenges posed by continually evolving pathogen populations. The limited number of new resistance genes available in the gene pool of crop cultivars has shifted the focus of breeders to wild ancestors, related species, and landrace collections, which constitute wide and underexploited resources of genetic variability (Hajjar and Hodgkin 2007).

In barley (Hordeum vulgare L.), the genetic variability that was present in old landraces was not exploited fully when modern breeding began (Fischbeck 1992, 2003); for this reason, barley is particularly well suited for the search for novel resistance genes and alleles in diverse materials. This has already been proved for resistance to powdery mildew (Blumeria graminis) in barley, because a substantial proportion of the resistance genes that have been discovered were found in landraces (Brown and Jørgensen 1991) and H. vulgare ssp. spontaneum (Jahoor and Fischbeck 1993; Schönfeld et al. 1996; Dreiseitl and Bockelman 2003; Řepková et al. 2006). Some of these genes have already been introgressed into elite germplasm to generate new cultivars (Backes et al. 2003).

The Spanish Barley Core Collection (SBCC) is a rich resource of landrace material that has scarcely been used for breeding (Igartua et al. 1998). To evaluate its potential to contribute new genetic diversity to enhance the disease resistance of the crop, it was screened with several fungal and viral pathogens (Silvar et al. 2010a). This study revealed promising levels of resistance to six isolates of powdery mildew in a remarkable number of accessions within the SBCC. To characterize this resistance, all lines from the SBCC were tested further for their reaction to a set of 27 isolates of $B$. graminis that exhibit different patterns of virulence/avirulence, as determined on a set of Pallas near-isogenic lines (Kølster et al. 1986; Silvar et al. 2011a). The results obtained for the 22 most resistant lines are presented in the current study. 
Additional work on a recombinant inbred line population derived from a cross between SBCC097 (one of the most resistant lines) and the cultivar Plaisant revealed the presence of two major quantitative trait loci (QTLs) for resistance on chromosome 7H (Silvar et al. 2010b). The alleles for resistance were derived from the Spanish parent and were localized in regions where major genes for resistance to powdery mildew ( $m l t$ and $M l f$ ) have been described already, albeit only in the ancestor H. vulgare ssp. spontaneum (Schönfeld et al. 1996; Řepková et al. 2006).

The main goals of the present work were to identify alternative genes that confer resistance to a broad spectrum of isolates of powdery mildew in other highly resistant landraces of Spanish barley, to investigate their genetic basis and, more specifically, to examine whether the resistance found in the highly resistant line SBCC145 is controlled by the same set of resistance genes as that in SBCC097.

\section{Materials and Methods}

\section{Plant and fungal materials}

Twenty-two landrace-derived inbred lines that belong to the SBCC (Igartua et al. 1998; Lasa 2008) and the German cultivar Beatrix were used for this study. All the SBCC lines are six-row barley, with a high level of resistance to powdery mildew (Silvar et al. 2010a; Silvar et al. 2011a). A doubled haploid $(\mathrm{DH})$ population was derived by anther culture from the $\mathrm{F}_{1}$ generation of a cross between the resistant line SBCC145 and Beatrix. Beatrix (Viskosa/Pasadena) is a spring, two-row barley cultivar with moderate resistance to powdery mildew. It carries the resistance genes Mla12 on chromosome $1 \mathrm{H}$ and MlLa on chromosome $2 \mathrm{H}$ (Bundessortenamt 2009). SBCC145, as is shown below, is resistant to a large number of powdery mildew isolates, including three that were found to be virulent for SBCC097. The population consists of 482 lines, of which a subset of 190 were used in the current study. The sample size was chosen as a compromise between the genotyping cost and the information gained. The sample size was appropriate to detect QTLs in a DH population. Lines 
were selected on the basis of their resistance to yet another disease, scald (Rhynchosporium secalis). The reason for this was that this population was constructed with a dual purpose, because SBCC145 displays high levels of resistance to both scald and powdery mildew. The entire population had already been phenotyped for scald resistance, and 190 lines with clear-cut phenotypic responses were selected for genotyping. The results for scald resistance will be presented, together with those for another population, in a future manuscript.

Twenty-seven isolates of B. graminis f. sp. hordei that are held in the collection of the Julius Kühn Institute in Kleinmachnow (Germany) were chosen on the basis of their pattern of virulence/avirulence in a set of 34 differential lines carrying known resistance genes present in European germplasm (Silvar et al. 2011a), including 16 near-isogenic lines from the Pallas differential set (Brown and Jørgensen 1991). Two of the isolates (211 and 224) were selected for further inoculation of the DH population on the basis of their pattern of virulence in the parental lines SBCC145 (resistant) and Beatrix (susceptible). These isolates infect the cultivar Beatrix, and are virulent on lines carrying Mla12 and MLLa (the resistance genes carried by Beatrix). SBCC145 displayed a type 1 infection in both cases, whereas Beatrix turned out to be highly susceptible to both isolates, with a score of 3 or 4 .

\section{Disease assessment}

Resistance of the SBCC lines to the 27 isolates of B. graminis was assessed by a detached leaf assay (Shtaya et al. 2007). Briefly, leaf segments from primary leaves were excised and placed on Petri dishes that contained $0.6 \%$ agar and $30 \mathrm{ppm}$ benzimidazole. Inoculation was carried out by blowing spores from the infected leaves over the leaf segments using a settling tower. A glass slide was placed in the settling tower to monitor inoculum density, which was adjusted to give approximately 2-4 conidia $\mathrm{mm}^{-2}$. The susceptible cultivar Hanna was used as a positive control. Twelve days after inoculation, the infection types (including intertypes) were recorded on a scale of $0-4$ in accordance with the scale put forward by Jahoor (1986). Plants with scores that were equal to or lower than 2 
were classified as resistant, whereas plants with scores above 2 were included in the susceptible group.

The evaluation of disease in the SBCC145 $\times$ Beatrix population was conducted in a greenhouse, with plants grown under $16-\mathrm{h}$ daily photoperiod at day-night temperatures of $22-17^{\circ} \mathrm{C}$. Five barley seedlings from each DH line were inoculated artificially. The susceptible cultivars Haisa and Igri were used as controls for inoculum density, and were included alternatively at a frequency of 1 control every ten DH lines. The susceptible controls displayed high and homogeneous infection rates (Haisa, 3-4; Igri, 3) across the experiment, which indicated the homogeneous experimental conditions. Eight days after inoculation, the infection on the primary leaves of the seedlings was scored on the same scale of $0-4$ as described above.

\section{Linkage and QTL analysis}

Total genomic DNA was isolated from frozen leaves using the NucleoSpin Plant II Minikit (Macherey-Nagel). Genotyping assays were performed with the first 1,536 SNP Illumina GoldenGate Oligonucleotide Pool Assay developed for barley (BOPA1) (Close et al. 2009) at the Southern California Genotyping Consortium (Los Angeles, CA, USA). SNPs were designated by their BOPA1 number. Information regarding the translation of BOPA1 numbers to SNP names, pilot OPA numbers (POPA) and HarvEST unigene assemblies \#32 and \#35 is available in Close et al. (2009).

A linkage map was constructed with JoinMap 4.0 (van Ooijen 2006), using Kosambi's map function and a minimum logarithm of the odds ratio (LOD score) of 5.

QTL analysis was performed using MapQTL 5.0 (van Ooijen 2004). The interval mapping (IM) procedure was used in a preliminary analysis to identify the major QTLs and to detect significantly associated markers. These markers were then used as cofactors to fit the multiple QTL model (MQM) (Jansen and Stam 1994). MQM was repeated iteratively by adding significant 'peak 
markers' at each step as co-factors, until a stable LOD profile was reached. The LOD threshold for detecting QTLs was calculated by a permutation test with 1,000 iterations and a genome-wide significance level of 0.05 .

Possible interactions between the identified QTLs were analysed using the unbalanced analysis of variance procedure implemented in Genstat release 12.1 (VSN International Ltd). The markers closest to the QTLs were included as fixed factors and their interaction was tested against the residual variance (due to the variation within each allelic class).

\section{Results}

\section{Phenotyping}

SBCC lines were characterized in terms of resistance to powdery mildew by the detached leaf assay, using a set of 27 isolates of B. graminis f. sp. hordei (Silvar et al. 2011a). In the present study, we report data on 22 of these lines, which were found to be resistant to over $50 \%$ of the isolates. No single SBCC line was resistant to all 27 isolates on the detached leaf assay. The landrace SBCC141 possessed the highest overall resistance (mean score 0.89). Other lines, such as SBCC014, SBCC036, SBCC042, SBCC058, and SBCC145, all presented average resistance values that were close to or just above 1, as did SBCC097 (Table 1). In terms of the number of infecting isolates, the widest range of resistance was found in three lines -SBCC097, SBCC141 and SBCC145- which were resistant to 23 out of the 27 isolates of $B$. graminis tested. The four isolates that caused disease differed among these three lines (Table 1). The correlation coefficients for the disease scores were calculated among lines in order to find resistance profiles that were complementary to that of SBCC097. Lines SBCC058, SBCC0141 and SBCC145 presented the most distinct profiles from that of SBCC097 with correlation coefficients very close to 0 . Furthermore, they were resistant to at least three of the four isolates that were virulent for SBCC097 (Table 1). Taking all these results together, SBCC141 and SBCC145 were identified as the best 
potential sources of resistance to powdery mildew that differed from those carried by SBCC097. The fact that SBCC145 also exhibited resistance to other diseases (data not shown) prompted us to produce a $\mathrm{DH}$ population with this line.

The parents, SBCC145 and Beatrix, and the DH population, were infected with two B. graminis isolates (211 and 224). SBCC145 displayed a type 1 infection in response to both isolates, whereas Beatrix turned out to be highly susceptible to both isolates, with a score of 3-4. Inoculation with both isolates resulted in a continuous distribution of phenotype frequencies, which suggested a quantitative inheritance of resistance (Fig. 1). The distributions of the resistance scores for the two isolates were similar ( $\mathrm{P}=0.67$ according to a Kolmogorov-Smirnoff two-sample test). Neither of them conformed to a normal distribution $(\mathrm{P}<0.01$, Shapiro-Wilk test). Both distributions were platykurtic (kurtosis of -1.0 and -1.1 , respectively), and the one for isolate 211 also had a marked positive skewedness.

Transgressive segregation was rare, with only one line exceeding the resistant parental value for isolate 224. For both isolates, the distribution of disease scores was skewed slightly towards resistance, with a population mean lower than the mid-parent value (Fig. 1). The Pearson correlation coefficient of disease scores against both isolates was high (0.77) and significant $(\mathrm{P}<0.001)$.

\section{Genetic map}

Out of 1,536 SNPs analysed by BOPA1, 698 were found to be polymorphic between SBCC145 and Beatrix. Among these, two markers with GenTrain scores below 0.5 (an internal quality control for SNP scoring), five markers with missing data above 20\%, and 12 markers with high proportions of heterozygous allele calls were removed. A final set of 679 SNPs was considered for further evaluation. Alleles were assigned in the DH lines on the basis of alleles present in the parental lines. A linkage map was constructed and all 679 markers were integrated into seven linkage groups 
(LOD score of 5.0) that corresponded to the seven chromosomes of barley (Fig. S1). Six DH lines were discarded on the basis of marker identity, five were identical to another DH line, and one line was off-type, with inconsistent markers that constituted over $20 \%$ of the total. Therefore, the final mapping population included $184 \mathrm{DH}$ lines. The identity and polarity of linkage groups were determined by comparison with a previously published consensus map (Close et al. 2009). Chromosome $5 \mathrm{H}$ had the highest number of markers (124), whereas chromosome $1 \mathrm{H}$ had the lowest (77). The total map length was $1,236.5 \mathrm{cM}$, with an average distance between markers of $3 \mathrm{cM}$, excluding co-segregating markers. The shortest chromosome was $6 \mathrm{H}(142 \mathrm{cM})$ and the longest chromosome was 5H (209.2 cM). The BOPA1 markers were well distributed, except for four gaps (20-30 cM) in chromosomes $1 \mathrm{H}, 3 \mathrm{H}$ and two on $7 \mathrm{H}$. A total of 278 markers co-segregated in clusters (four or more markers) on chromosomes $2 \mathrm{H}, 3 \mathrm{H}, 5 \mathrm{H}$ and $6 \mathrm{H}$. The largest cluster, with 32 co-segregating markers, was on the centromeric region of chromosome $3 \mathrm{H}$.

The allele frequencies of the DH population revealed segregation distortions, with deviations from the expected ratio of 1:1. Major distortions in favor of the Beatrix allele were observed for $5 \mathrm{H}$ and $7 \mathrm{H}$, whereas regions of chromosomes $3 \mathrm{H}$ and $6 \mathrm{H}$ showed some distortion in favor of the SBCC145 allele, but less marked and barely significant (Fig. S2).

\section{QTL analysis}

A total of four QTLs were detected (Fig. 2, Table 2). The main one was located in a region on chromosome $6 \mathrm{H}$ (bin 15; see Close et al. 2009) and was associated clearly with resistance to both isolates of B. graminis (211 and 224). This important QTL exhibited a LOD score from 36.2 (isolate 224) to 44.4 (isolate 211 ) and accounted for $59.6 \%$ and $58.5 \%$ of the phenotypic variance, respectively. Two minor QTL on chromosome $2 \mathrm{H}$ (bins 5 and 9) were associated with reaction to isolate 211. These two QTLs displayed LOD scores that ranged from 3.7 to 6.4. The alleles at these QTLs determined 2.7 and $4.6 \%$ of the phenotypic variance, respectively. A QTL on the short arm 
of chromosome $7 \mathrm{H}$ (bin 2) was identified for the response to isolate 224. This QTL exhibited a LOD of 3.2 and explained $2.9 \%$ of the phenotypic variation. For all QTLs, the resistance allele derived from the Spanish parent SBCC145 (Table 2).

Interactions between QTLs were evaluated by analyses of variance carried out using all the QTLs detected for each isolate as sources of variation. For this approach, the marker closest to each QTL was used to define the genotype at each locus. Epistatic interactions were detected for isolate 211 between each QTL on chromosome $2 \mathrm{H}$ and the QTL on $6 \mathrm{H}$. The effect of each QTL on $2 \mathrm{H}$ was evident only for plants that carried the susceptible allele at the QTL on $6 \mathrm{H}$, that is, plants that carried the resistant allele at $6 \mathrm{H}$ showed a remarkable level of resistance that masked the resistance contributed by either QTL on 2H (Fig. 3). In contrast, no QTL $\times$ QTL interaction was detected for isolate 224, which suggested primarily additive effects for all QTL in this case. The group of plants that carried both favourable alleles against isolate 224 (both from SBCC145) showed significantly better resistance than those plants with the same allelic composition as Beatrix (Fig. 3).

\section{Discussion}

A major focus in current plant breeding is the enrichment of the breeding gene pool with favourable alleles from diverse germplasm which will eventually lead to the release of new improved varieties and their adoption by farmers. This is especially true in relation to breeding for disease resistance, because wild relatives and landraces have consistently contributed new resistance genes to many crops (Huxley 2005). Screening the SBCC for disease resistance revealed the existence of some lines with remarkable levels of resistance to powdery mildew (Silvar et al. 2010a). Further work showed that 22 of these landraces were resistant to at least 14 out of a panel of 27 isolates of $B$. graminis. Each of these isolates presents specific infection spectra over a panel of differential lines (Silvar et al. 2011a). Each line in this panel, used to discriminate among B. graminis isolates, carry a different assortment of the powdery mildew resistance genes found in European germplasm (some 
just one, some several genes). The 27 isolates used in this work, therefore, represent a good sampling of the fungus diversity in terms of profile of infection over European barley. Different molecular and phenotypic analyses have refuted that this resistance is mlo-type in each case (Silvar et al. 2010b, Silvar et al. 2011a).

Among these 22 landrace-derived inbred lines. three displayed a broad spectrum of resistance to 23 out of 27 isolates, namely SBCC097, SBCC141, and SBCC145. Interestingly, these three lines showed distinctive resistance spectra to the 23 isolates, that is, they were not infected by the same set of isolates. This suggests the presence of different genes, alleles, or gene combinations in these three lines. Several studies have been carried out in recent decades with the aim of identifying potential genes or alleles in landrace collections (Czembor 1999, 2000). Normally, these studies have involved tests for resistance that are based on the gene-for-gene hypothesis of Flor (1971). However, putative genes or alleles can only be confirmed through the evaluation of progenies from crosses among the appropriate genotypes, or more recently, through genetic association studies based on linkage disequilibrium (Comadran et al. 2009; Cockram et al. 2010; Roy et al. 2010). The resistance of SBCC097 had already been investigated in a previous study with a recombinant inbred line (RIL) population developed for this purpose (Silvar et al. 2010b), and the specific goal of the present work was to investigate whether the resistance identified in SBCC145 was controlled by the same set of resistance genes as that in SBCC097. The SBCC145 line was selected for its high overall resistance and, in particular, because it was resistant to three isolates virulent to SBCC097, which should maximize the possibility of finding complementary resistance genes. Unfortunately, the genetic background of Beatrix precluded screening with these three isolates as well as the four isolates that had been used for the original phenotyping of SBCC097×Plaisant (data not shown).

The SBCC145×Beatrix population was genotyped using BOPA1. In general, marker positions estimated for SBCC $145 \times$ Beatrix were consistent with the previously published consensus map (Close et al. 2009). The average rate of polymorphism between the parents was approximately $46 \%$, 
which is similar to the level found by Sato and Takeda (2009) for the Haruna Nijo $\times$ H602 population. Among 698 polymorphic markers, 278 (40\%) showed co-segregation, in particular within linkage groups on chromosomes $3 \mathrm{H}$ and 5H. Segregation distortion in favor of the SBCC145 alleles was limited to small segments of four chromosomes, and none of them very pronounced. In contrast, distortion in favor of Beatrix alleles was detected on five chromosomes, with relative frequencies higher than $40 \%$ in some regions of chromosomes $5 \mathrm{H}$ and $7 \mathrm{H}$, which corresponded to the positions of major vernalization genes (VrnH1 and $\mathrm{VrnH} 3$, respectively) (data not shown). These results might be explained by inadvertent selection applied at the population multiplication step in the greenhouse. We can speculate that this step increased the frequency of individuals that carried the Beatrix spring VrnH1 allele, to the detriment of the SBCC145 intermediate VrnH1 allele, which might have reduced the fitness of the plants in the greenhouse. In any case, the regions that contained the QTLs detected in this study were not affected by distortion. Indeed, even if this were not the case, the dense map obtained for our population would make up for the loss of power due to segregation distortion in the QTL analysis (Xu 2008).

Quantitative trait loci for powdery mildew resistance have been mapped to all chromosomes in barley (Heun 1992; Williams 2003; Yun et al. 2005). Some of these QTLs coincide with major genes but others are localized in chromosomal regions that had not been identified previously in this context. The major QTLs on chromosome $6 \mathrm{H}$ identified for the two isolates in our study were exactly at the same position. However, the minor QTLs on $2 \mathrm{H}$ and $7 \mathrm{H}$, which explained smaller proportions of the variance, varied from isolate to isolate. To the best of our knowledge (Friedt and Ordon 2007; Ordon 2009), a few QTLs for resistance with low significance and one resistance gene (Mlh) have been identified on chromosome 6H (Saghai Maroof et al. 1994; Jørgensen 1994, Backes et al. 1995; Falak et al. 1999; Backes et al. 2003). Although the exact position of the Mlh gene is unknown, it seems to be located on the short arm of chromosome 6H (Ordon 2009); therefore, its co-localization with our QTLs was refuted early on. Recently, Aghnoum et al. (2010) have 
identified two QTL on chromosome $6 \mathrm{H}$ that are related to basal resistance to powdery mildew in barley. The locations of these QTLs (on bins 6H_06 and 6H_08-10) do not coincide with the location identified in our present work (bin 6H_15). Li and Zhou (2011) reported a QTL with minor effects on the distal part of $6 \mathrm{HL}$ in the Yerong $\times$ Franklin population. The DArT marker associated with this QTL (bPb-2410) is located 1 cM proximal to marker 11_1351 (Szücs et al. 2009), which is one of the flanking markers for the QTL identified in the present work. This shared position suggests that they both refer to the same locus. However, the magnitude of the effect observed and the proportion of phenotypic variation accounted for by our QTL, led us to think that the alleles identified in SBCC145 $\times$ Beatrix might be different from those present in the Yerong $\times$ Franklin population.

Several QTL that confer resistance to B. graminis have been identified on chromosome $2 \mathrm{H}$, in particular on the short arm (Saghai Maroof et al. 1994; Backes et al. 2003; von Korff et al. 2005; Řepková et al. 2006; Shtaya et al. 2006). Recently, Aghnoum et al. (2010) have reported several QTL for resistance to powdery mildew on chromosome 2H (bins 2H_04 to 2H_07). Indirect map comparisons between consensus maps by Szücs et al. (2009) and Aghnoum et al. (2010) suggest that 2H QTL1 occupies the same position as the QTL Rbgq8, which was described by Aghnoum et al. (2010) in the Nure $\times$ Tremois population.

The short arm of chromosome 7H (7HS) has often been reported to be a "hot spot" for resistance genes and QTLs for different diseases (Ayliffe et al. 2000; Brueggeman et al. 2002; Bulgarelli et al. 2004; Drader et al. 2009). Several studies using different populations (Schönfeld et al 1996; Řepková et al. 2006; Aghnoum et al. 2010; Silvar et al 2010b) have identified resistance QTL in the same region of $7 \mathrm{HS}$ which were attributed to the mlt gene in most cases. The resistance QTL identified on chromosome 7HS for isolate 224 was located near this region. However, fine mapping of the SBCC097×Plaisant QTL (unpublished data) indicated that the QTL from SBCC145 mapped approximately $10 \mathrm{cM}$ distal of this region, according to the consensus map (Close et al. 2009). The 
same distinction was found when the positions of peak markers for our QTL and the position of the QTL presented in Aghnoum et al. (2010) were compared. On the basis of common markers between the consensus maps by Aghnoum et al. (2010) and Close et al. (2009), we conclude that the two QTL map to different bins. These findings seem to indicate that the QTL on 7HS is not co-localized with the mlt gene.

The presence of genes and QTL related to defence against infection at the same location on maps has been reported in other studies (Wang et al. 2001; Marcel et al. 2007). The SNP marker 11_0509 on $6 \mathrm{H}$ is derived from an EST sequence that probably encodes a callose synthase-like protein, whereas the SNP marker 11_0016 on 7H is derived from an EST that encodes a peroxidase (Close et al. 2009). Both callose deposition and peroxidase accumulation are common plant responses to pathogen infection. Trujillo et al. (2004) and Johrde and Schweizer (2008) have even reported that these processes participate in defence response of barley against powdery mildew. We cannot conclude definitely that these genes are responsible for the types of resistance observed in the Spanish lines, because our findings cannot prove this; however, the coincidence is worth noting and might offer new avenues for research on this issue.

The large effect QTL found on chromosome $6 \mathrm{H}$ is located between the last two markers of this chromosome, in an interval of $3.4 \mathrm{cM}$. These markers also lie at the two most distal positions in the consensus map of Close et al. (2009), separated by only $1.44 \mathrm{cM}$. This is a rather small region for a QTL, and thus the prospects for further fine mapping are promising. In addition, the direct use of lines from this population for marker assisted selection (MAS) might be profitable. Beatrix contributed elite spring germplasm and at least two resistant DH lines displayed small SBCC145 introgression segments in the QTL region (which spanned just the last two markers of the chromosome), on background that was close to $70 \%$ Beatrix (data not shown).

Given that this landrace-derived line SBCC145 showed resistance to 23 out of 27 isolates, we can describe its resistance as having a broad spectrum because these isolates displayed a wide range of 
virulence when inoculated on a set of differential lines (Silvar et al. 2011a). The same can be stated for the landrace SBCC097, which exhibits resistance to a different set of isolates to SBCC145 (Silvar et al. 2010b). The entire SBCC has been evaluated with the Illumina BOPA1 Platform (unpublished data). Investigation of the chromosomal regions on $6 \mathrm{H}$ and $7 \mathrm{H}$ that confer resistance to different B. graminis isolates did not reveal the presence of any consistent haplotype that was shared by the resistant lines. The genetic basis underlying the resistance of SBCC145 to the isolates that were virulent to SBCC097 $(120,125,179)$ could not be ascertained in this population, because Beatrix also exhibited resistance to them. We do not know for certain whether the large effect QTL identified on $6 \mathrm{H}$ is also responsible for the resistance to these isolates; however, this can be tested in future populations that are currently under development, with SBCC145 as one of the parents. Given that QTLs for resistance to infection in SBCC097 and SBCC145 are located in different chromosomal regions, it should be easy to pyramid these loci. We can speculate that their combination may result in a more effective, broader spectrum, and potentially more durable resistance to powdery mildew. Epistasis among these genes, if present, might contribute to an even higher level or broader spectrum of resistance. However, this cannot be ascertained until appropriate plant materials, combining the two QTLs from SBCC097 and the main QTL from SBCC145, have been developed. Indeed, attempts to pyramid basal resistance genes for powdery mildew have already resulted in successful transgressive segregation (Aghnoum and Nicks 2011). Although further research into the nature of the resistances identified is necessary, we can conclude that the SBCC is a very diverse and valuable source of novel disease resistances against powdery mildew. The use of highly efficient markers and dense maps renders these landraces particularly useful for breeding, especially in combination with cheap and efficient techniques for SNP genotyping (Silvar et al. 2011b).

\section{Acknowledgments}


This work was funded by the Spanish Ministry of Science and Innovation (projects GEN200628560-E, AGL2007-63625, and Plant-KBBE ExpResBar, EUI2009-04075), and co-funded by the European Regional Development Fund. CS holds an I3P postdoctoral contract from CSIC. CS was supported by mobility fellowships from the Deutsche Forschungsgemeinschaft (DFG), CSIC, Fundación Caja Inmaculada and COST Action FA0604 (Tritigen).

\section{References}

Aghnoum R, Marcel TC, Johrde A, Pecchioni N, Schweizer P, Niks RE (2010) Basal host resistance of barley to powdery mildew: connecting quantitative trait loci and candidate genes. Mol Plant Microbe Interact 23:91-102

Aghnoum R, Niks RE (2011) Transgressive segregation for very low and high levels of basal resistance to powdery mildew in barley. J Plant Physiol 168:45-50

Ayliffe MA, Collins NC, Ellis JG, Pryor A (2000) The maize rp1 rust resistance gene identifies homologues in barley that have been subjected to diversifying selection. Theor Appl Genet 100:1144-1154

Backes G, Graner B, Foroughi-Wehr G, Fischbeck G, Wenzel G, Jahoor A (1995) Localization of quantitative trait loci (QTL) for agronomic important characters by the use of a RFLP map in barley (Hordeum vulgare L.). Theor Appl Genet 90:294-302

Backes G, Madsen LH, Jaiser H, Stougaard J, Herz M, Mohler V, Jahoor A (2003) Localization of genes for resistance against Blumeria graminis f.sp. hordei and Puccinia graminis in a cross between a barley cultivar and a wild barley (Hordeum vulgare ssp. spontaneum) line. Theor Appl Genet 106:353-362

Bulgarelli D, Collins NC, Tacconi G, Dellaglio E, Brueggeman R, Kleinhofs A, Stanca AM, Valè G (2004) High-resolution genetic mapping of the leaf stripe resistance gene Rdg2a in barley. Theor Appl Genet 108:1401-1408

Brown JKM, Jørgensen, JH (1991) A catalogue of mildew resistance genes in European barley varieties. In: Jørgensen, JH (ed.). Integrated control of cereal mildews: virulence patterns and their change 263-286. Risø National Laboratory, Roskilde, Denmark

Brueggeman R, Rostoks N, Kurdna D, Kilian A, Han F, Chen J, Druka A, Steffenson BJ, Kleinhofs A (2002) The barley stem rust-resistance gene Rpg1 is a novel disease-resistance gene with homology to receptor kinases. Proc Natl Acad Sci USA 99:9328-9333

Bundessortenamt. 2009. Ergänzende feststellungen zur anfälligkeit für krankheiten und schädlinge. In: Beschreibende Sortenliste für Getreide, mais, ölfrüchte, leguminosen, hackfrüchte. pp.44-49

Close TJ, Bhat PR, Lonardi S, Wu Y, Rostoks N, Ramsay L, Druka A, Stein N, Svensson J, Wanamaker S, Bozdag S, Roose M, Moscou M, Chao S, Varshney R, Szucs P, Sato K, Hayes P, Matthews D, Kleinhofs A, Muehlbauer G, DeYoung J, Marshall D, Madishetty K, Fenton R, Condamine P, Graner A, Waugh R (2009) Development and implementation of high-throughput SNP genotyping in barley. BMC Genomics 10:582 
Cockram J, White J, Zuluaga D, Comadran J, Macaulay M, Liu Z, Kearsey M. Werner P, Harrap D, Tapsell C, Liu H, Stein N, Schulte D, Steurnagel B, Marshall DF, Thomas WTB, Ramsay L, Mackay I, Balding DJ, the AGOUEB Consortium, Waugh R, O'Sullivan DM (2010) Genome-wide association mapping of morphological traits to candidate gene resolution in the un-sequenced barley genome Proc Natl Acad Sci USA 107: 21611-21616

Comadran J, Thomas WTB, van Eeuwijk F, Ceccarelli S, Grando S, Stanca AM, Pecchioni N. Akar T, Al-Yassin A, Benbelkacem A, Ouabbou H, Bort J, Romagosa I, Hackett CA, Russell JR (2009) Patterns of genetic diversity and linkage disequilibrium in a highly structured Hordeum vulgare association-mapping population for the Mediterranean basin. Theor Appl Genet 119: 175-187

Czembor JH (1999) Resistance to powdery mildew in barley landraces from Tunisia. Plant Breed Seed Sci 43:49-65

Czembor JH (2000) Resistance to powdery mildew in populations of barley landraces from Morocco. Genet Res Crop Evol 47: 439-450

Drader T, Johnson K, Brueggeman R, Kudrna D, Kleinhofs A (2009) Genetic and physical mapping of a high recombination region on chromosome $7 \mathrm{H}(1)$ in barley. Theor Appl Genet 118: 811-820

Dreiseitl A, Bockelman HE (2003) Sources of powdery mildew resistance in a wild barley collection. Genet Resour Crop Evol 50:345-350

Falak I, Falk DE, Tinker NA, Mather DE (1999) Resistance to powdery mildew in a doubledhaploid barley population and its association with marker loci. Euphytica 107:185-192

Fischbeck G (1992) Barley cultivar development in Europe. Success in the past and possible changes in the future In: Munk L (ed) Proceedings of 6th International Barley Genetics Vol II. Munksgaard Int Publ Ltd Copenhagen, pp 887-901

Fischbeck G (2003) Diversification through breeding. In: von Bothmer R, van Hintum T, Knuepffer H, Sato K (eds) Diversity in barley. Elsevier, Amsterdam, pp 29-52

Friedt W, Ordon F (2007) Molecular markers for gene pyramiding and disease resistance breeding in barley. In: Varshney RV, Tuberosa R (eds) Genomics-assisted crop improvement: Vol. 2: Genomics application in crops. Springer, Netherlands, pp 81-101

Flor HH (1971) Current status of the gene-for-gene concept. Ann Rev Phytopathol 9: 275-296

Hajjar R, Hodgkin T (2007) The use of wild relatives in crop improvement: a survey of developments over the last 20 years. Euphytica 156:1-13

Heun M (1992) Mapping quantitative powdery mildew resistance of barley using a restriction fragment length polymorphism map. Genome 35:1019-1025

Huxley A (2005) Green inheritance. University of California Press, Berkeley and Los Angeles, California

Igartua E, Gracia MP, Lasa JM, Medina B, Molina-Cano JL, Montoya JL, Romagosa I (1998) The Spanish barley core collection. Genet Resour Crop Evol 45:475-481

Jahoor A (1986) Mehltauresistenz israelischer Wildgersten - Resistenzspektrum, Vererbung und Lokalisierung. Dissertation, Technische Universität München, Freising-Weihenstephan

Jahoor A, Fischbeck G (1993) Identification of new genes for mildew resistance of barley at the Mla locus in lines derived from Hordeum spontaneum. Plant Breed 110:116-122

Jansen R, Stam P (1994) High resolution of quantitative traits into multiple loci via interval mapping. Genetics 136:1447-1455 
Johrde A, Schweizer P (2008) A class III peroxidase specifically expressed in pathogen-attacked barley epidermis contributes to basal resistance. Mol Plant Pathol 9:687-696

Jørgensen JH (1994) Genetics of powdery mildew resistance in barley. Critic Rev Plant Sci 13:97119

Kølster P, Munk L, Stølen O, Løhde J (1986) Near-isogenic barley lines with genes for resistance to powdery mildew. Crop Sci 26:903-907

Lasa JM (2008) Spanish Barley Core Collection. Monografías INIA: Serie Agrícola, n. 25. Instituto Nacional de Tecnología Agraria y Alimentaria, Madrid

Li HB, Zhou MX (2011) Quantitative trait loci controlling barley powdery mildew and scald resistances in two different barley doubled haploid populations. Mol Breeding 27: 479-490

Marcel TC, Varshney RK, Barbieri M, Jafary H, de Kock MJD, Graner A, Niks RE (2007) A highdensity consensus map of barley to compare the distribution of QTL for partial resistance to Puccinia hordei and of defence gene homologues. Theor Appl Genet 114:487-500.

Ordon F (2009) Coordinator's Report: Disease and Pest resistance genes. In: Barley Genetics Newsletter 39, Udda Lundqvist (ed), pp 58-69

Řepková J, Dreiseitl A, Lízal P, Kyjovská Z, Teturová K, Psotková R, Jahoor A (2006) Identification of resistance genes against powdery mildew in four accessions of Hordeum vulgare ssp spontaneum. Euphytica 151:23-30

Roy JK, Smith KP, Muehlbauer GJ, Chao S, Close TJ, Steffenson BJ (2010) Association mapping of spot blotch resistance in wild barley. Mol Breeding 26:243-256

Saghai Maroof MA, Blyashev RB, Zhang Q (1994) Molecular marker analysis of powdery mildew resistance in barley. Theor Appl Genet 88: 733-740

Sato K, Takeda K (2009) An application of high-throughput SNP genotyping for barley genome mapping and characterization of recombinant chromosome substitution lines. Theor Appl Genet 119:613-619

Schönfeld M, Ragni A, Fischbeck G, Jahoor A (1996) RFLP mapping of three new loci for resistance genes to powdery mildew (Erysiphe graminis f. sp. hordei) in barley. Theor Appl Genet 93:48-56

Shtaya MJY, Marcel TC, Sillero JC, Niks RE, Rubiales D (2006) Identification of QTLs for powdery mildew and scald resistance in barley. Euphytica 151:421-429

Shtaya MJY, Sillero JC, Flath K, Pickering R, Rubiales D (2007) The resistance of leaf rust and powdery mildew of recombinant lines of barley (Hordeum vulgare L.) derived from $H$. vulgare x $H$. bulbosum crosses. Plant Breed 126:259-267

Silvar C, Casas AM, Kopahnke D, Habekuß A, Schweizer G, Gracia MP, Lasa JM, Ciudad FJ, Molina-Cano JL, Igartua E, Ordon F (2010a) Screening the Spanish Barley Core Collection for disease resistance. Plant Breed 129:45-52

Silvar C, Dhif H, Igartua E, Kopahnke D, Gracia MP, Lasa JM, Ordon F, Casas AM, (2010b) Identification of quantitative trait loci for resistance to powdery mildew in a Spanish barley landrace. Mol Breed 25:581-592

Silvar C, Flath K, Kopahnke D, Gracia MP, Lasa JM, Casas AM, Igartua E, Ordon F (2011a) Analysis of powdery mildew resistance in the Spanish Barley Core Collection. Plant Breed 130:195-202 
Silvar C, Perovic D, Casas AM, Igartua E, Ordon F (2011b) Development of a cost-effective pyrosequencing approach for SNP genotyping in barley. Plant Breed 130: 394-397

Szücs P, Blake VC, Bhat PR, Chao S, Close TJ, Cuesta-Marcos A, Muehlbauer GJ, Ramsay L, Waugh R, Hayes PM (2009) An Integrated Resource for Barley Linkage Map and Malting Quality QTL Alignment. The Plant Genome 2:134-140

Trujillo M, Troeger M, Niks RE, Kogel KH, Hückelhoven R (2004) Mechanistic and genetic overlap of barley host and non-host resistance to Blumeria graminis. Mol Plant Pathol 5:389-396

van Ooijen JW (2006) JoinMap 4, software for the calculation of genetics linkage maps in experimental populations. Kyazma, BV, Wageningen, Netherlands

van Ooijen JW (2004) MapQTL ${ }^{\circledR} 5$, Software for the mapping of quantitative trait loci in experimental populations. Kyazma BV, Wageningen, Netherlands

von Korff M, Wang H, Léon J, Pillen K (2005) AB-QTL analysis in spring barley. I. Detection of resistance genes against powdery mildew, leaf rust and scald introgressed from wild barley. Theor Appl Genet 111:583-590

Wang Z, Taramino G, Yang D, Liu G, Tingey SV, Miao GH, Wang GL (2001) Rice ESTs with disease-resistance gene- or defense response gene-like sequences mapped to regions containing major resistance genes or QTL. Mol Genet Genomics 265:302-310

Williams KJ (2003) The molecular genetics of disease resistance in barley. Aust J Agric Res 54:1065-1079

Xu S (2008) Quantitative Trait Locus Mapping Can Benefit From Segregation Distortion. Genetics 180: $2201-2208$

Yun SJ, Gyenis L, Hayes PM, Matus I, Smith KP, Steffenson BJ, Muehlbauer GJ (2005)

Quantitative trait loci for multiple disease resistance in wild barley. Crop Sci 45:2563-2572 
Table 1 Infection types ( 0 , resistant -4 , susceptible) of 22 landrace-derived inbred lines from the SBCC and cultivar Beatrix with respect to 27 isolates of $B$. graminis. Linear correlation coefficients for the reaction norm of each line with SBCC097 are also presented (intermediate infection types considered as 1.5, 2.5 and $3.5)$.

\section{Blumeria graminis isolates}

\begin{tabular}{|c|c|c|c|c|c|c|c|c|c|c|c|c|c|c|c|c|c|c|c|c|c|c|c|c|c|c|c|c|c|}
\hline Line & 75 & 78 & 79 & 82 & 114 & 116 & 118 & 120 & 121 & 122 & 125 & 126 & 127 & 164 & 167 & 168 & 170 & 176 & 178 & 179 & 180 & 199 & 211 & 212 & 221 & 224 & 225 & Mean & $\begin{array}{r}\text { Correlation } \\
\text { coefficient }\end{array}$ \\
\hline SBCC004 & 1 & 1 & 0 & 1 & 0 & 4 & $2-3$ & 1 & 0 & 0 & 0 & 4 & 0 & $2-3$ & 3 & 1 & 4 & 0 & 1 & 0 & 4 & 1 & 0 & 0 & 3 & 1 & 0 & 1.30 & -0.19 \\
\hline SBCC009 & 3 & 3 & 0 & 0 & 0 & 0 & $2-3$ & $2-3$ & 0 & 0 & 0 & 0 & 0 & 0 & 0 & 3 & 3 & 0 & 3 & 0 & 4 & 4 & 3 & 3 & 0 & 0 & 0 & 1.26 & -0.06 \\
\hline SBCC012 & $3-4$ & $2-3$ & $1-2$ & 2 & 1 & $2-3$ & 2 & 1 & 0 & $2-3$ & $2-3$ & $1-2$ & 2 & $2-3$ & 2 & 2 & 3 & 2 & 2 & $2-3$ & 2 & $3-4$ & 2 & $2-3$ & $2-3$ & $2-3$ & $2-3$ & 2.07 & 0.03 \\
\hline SBCC014 & 0 & 1 & 0 & 0 & 0 & 0 & 0 & 4 & 1 & 0 & 1 & 0 & 0 & 0 & 0 & 0 & 0 & 0 & 1 & 3 & 0 & 0 & 3 & 0 & 4 & 4 & 4 & 0.96 & 0.45 \\
\hline SBCC018 & 4 & $3-4$ & $1-2$ & $2-3$ & $2-3$ & 2 & 0 & 0 & 0 & 2 & 1 & 0 & 0 & 0 & 0 & 4 & 3 & 2 & 3 & 0 & 3 & 4 & 3 & 3 & 2 & $1-2$ & 3 & 1.87 & -0.23 \\
\hline SBCC036 & 0 & 1 & 0 & 0 & 0 & 0 & 0 & $2-3$ & 1 & 1 & 0 & 1 & 0 & 0 & 0 & 1 & 0 & 0 & 1 & $2-3$ & 0 & 0 & 3 & 0 & 4 & 4 & 4 & 0.96 & 0.47 \\
\hline SBCC042 & 0 & 1 & 1 & 0 & 0 & 0 & 1 & 3 & 1 & 0 & 0 & 1 & 0 & 1 & 0 & 0 & 1 & 0 & 0 & 3 & 0 & 1 & 4 & 0 & 4 & 4 & 4 & 1.11 & 0.35 \\
\hline SBCC058 & $3-4$ & 3 & 1 & 0 & 0 & 0 & 1 & 0 & 0 & 1 & 0 & 1 & 0 & 1 & 0 & 3 & 0 & 1 & 3 & 0 & 0 & 3 & 3 & 3 & 0 & 0 & 0 & 1.02 & 0.04 \\
\hline SBCC062 & $2-3$ & 2 & 1 & 2 & 0 & 1 & 2 & 3 & 0 & $1-2$ & $2-3$ & 0 & 0 & 0 & 0 & 3 & 3 & 1 & $2-3$ & 0 & 3 & $3-4$ & 3 & $2-3$ & 3 & 0 & 0 & 1.56 & 0.02 \\
\hline SBCC063 & $2-3$ & $2-3$ & 2 & 2 & 0 & 2 & $1-2$ & 0 & 2 & $2-3$ & 3 & 0 & 1 & 2 & 3 & 3 & $2-3$ & 2 & $2-3$ & 1 & 3 & 3 & $2-3$ & $2-3$ & 2 & 3 & $2-3$ & 2.06 & -0.28 \\
\hline SBCC072 & 2 & 2 & 2 & $2-3$ & $2-3$ & 1 & $1-2$ & 3 & 0 & 2 & 3 & 2 & 2 & $1-2$ & 0 & 2 & $2-3$ & 2 & 2 & 3 & 4 & $2-3$ & 2 & 2 & 2 & 3 & $2-3$ & 2.09 & 0.33 \\
\hline SBCC078 & 4 & 2 & $1-2$ & 0 & $2-3$ & $2-3$ & 3 & 3 & 0 & 3 & 2 & 1 & 0 & 2 & 4 & $2-3$ & $2-3$ & 2 & $2-3$ & 0 & 0 & 2 & 0 & 3 & 0 & $2-3$ & 3 & 1.87 & -0.17 \\
\hline SBCC089 & 2 & 2 & 3 & 2 & 2 & 2 & 2 & 4 & 0 & 2 & $2-3$ & 3 & 2 & $2-3$ & 4 & $2-3$ & $2-3$ & $2-3$ & $2-3$ & 3 & 3 & 2 & 2 & 2 & 2 & 4 & 2 & 2.41 & 0.29 \\
\hline SBCC091 & $2-3$ & $1-2$ & 1 & 2 & 2 & 2 & $1-2$ & 3 & 0 & 2 & $2-3$ & $2-3$ & 2 & 2 & $2-3$ & $2-3$ & $2-3$ & 1 & $2-3$ & 3 & 0 & $1-2$ & 2 & 2 & 2 & 3 & 0 & 1.89 & 0.53 \\
\hline SBCC097 & 1 & $1-2$ & 0 & 1 & 0 & 0 & 1 & $2-3$ & 0 & $1-2$ & $2-3$ & 3 & 2 & 0 & 0 & 2 & 0 & 0 & $1-2$ & $2-3$ & 0 & 0 & 2 & 0 & 1 & 2 & 1 & 1.04 & - \\
\hline SBCC099 & 3 & $2-3$ & $2-3$ & $2-3$ & 3 & 0 & 1 & 0 & 0 & 1 & 2 & 0 & 0 & 1 & 0 & $2-3$ & 2 & 3 & $2-3$ & 0 & 1 & $2-3$ & 3 & 3 & 1 & 1 & 2 & 1.56 & -0.23 \\
\hline SBCC109 & $2-3$ & 4 & 2 & 2 & $2-3$ & 2 & $2-3$ & 4 & 0 & $1-2$ & $2-3$ & 0 & 0 & $2-3$ & 2 & $2-3$ & $2-3$ & 2 & 3 & 0 & 4 & 4 & $2-3$ & 3 & 2 & 2 & 1 & 2.17 & -0.25 \\
\hline SBCC119 & 2 & $2-3$ & 2 & 2 & 0 & $2-3$ & $2-3$ & $2-3$ & 0 & 2 & $2-3$ & 1 & 0 & 2 & 0 & 2 & 2 & $2-3$ & $2-3$ & 0 & 4 & $2-3$ & 3 & $2-3$ & 2 & 4 & $2-3$ & 1.96 & 0.00 \\
\hline SBCC124 & 3 & 2 & $1-2$ & 2 & 2 & 2 & 4 & 3 & 0 & 3 & $1-2$ & 0 & 2 & 2 & 3 & $2-3$ & $2-3$ & 1 & 1 & 0 & 0 & 2 & $1-2$ & 3 & 1 & 2 & 4 & 1.91 & -0.11 \\
\hline SBCC130 & 3 & 3 & 2 & 2 & 2 & 1 & 3 & $2-3$ & 0 & 3 & $1-2$ & 0 & 2 & $1-2$ & 0 & 3 & $2-3$ & 1 & 2 & 0 & 2 & 2 & 2 & 3 & 1 & 2 & 4 & 1.89 & 0.00 \\
\hline SBCC141 & 1 & $1-2$ & 1 & 0 & 0 & 0 & 1 & 0 & 0 & 0 & $2-3$ & 0 & 0 & 1 & 0 & 1 & $2-3$ & $2-3$ & 1 & 0 & 3 & 0 & 2 & 0 & 0 & 2 & 2 & 0.89 & -0.03 \\
\hline SBCC145 & 2 & 3 & $2-3$ & 0 & 0 & 1 & 0 & 1 & 1 & 0 & 1 & $2-3$ & 0 & 0 & 2 & $1-2$ & 2 & 0 & 2 & 0 & 2 & $2-3$ & 1 & 0 & 2 & 1 & 2 & 1.19 & -0.01 \\
\hline Beatrix & 3 & 4 & $2-3$ & $0-2$ & 1 & 1 & 2 & 0 & 0 & $0-1$ & 2 & 0 & 0 & $0-1$ & 0 & 1 & 0 & 3 & 0 & $2-3$ & $0-1$ & 2 & 3 & 1 & 2 & 3 & 4 & 1.46 & -0.09 \\
\hline
\end{tabular}


Table 2 Summary of QTLs for powdery mildew resistance detected in the SBCC145×Beatrix DH population in response to inoculation with B. graminis isolates 211 and 224.

\begin{tabular}{|c|c|c|c|c|c|c|c|}
\hline Trait & $\begin{array}{l}\text { QTL } \\
\text { No. }\end{array}$ & $\begin{array}{l}\text { Linkage } \\
\text { group }\end{array}$ & $\begin{array}{c}\text { QTL peak (cM) } \\
\text { (2-LOD conf. interval) }\end{array}$ & $\begin{array}{l}\text { Closest } \\
\text { marker }\end{array}$ & LOD & $\begin{array}{l}\text { Additive } \\
\text { effect }^{\mathrm{a}}\end{array}$ & $R^{2}(\%)^{b}$ \\
\hline \multirow[t]{3}{*}{ Isolate 211} & 1 & $2 \mathrm{H}$ & $56.3(49.3-59.6)$ & $11 \_1143$ & 3.7 & -0.12 & 2.7 \\
\hline & 2 & $2 \mathrm{H}$ & $110.3(108.3-112.3)$ & 11_0247 & 6.4 & -0.16 & 4.6 \\
\hline & 3 & $6 \mathrm{H}$ & $142(138-142)$ & 11_0509 & 44.4 & -0.55 & 58.5 \\
\hline \multirow[t]{2}{*}{ Isolate 224} & 2 & $6 \mathrm{H}$ & $142(138-142)$ & 11_0509 & 36.2 & -0.55 & 59.6 \\
\hline & 3 & $7 \mathrm{H}$ & $14.9(6.6-16.9)$ & 11_0016 & 3.2 & -0.13 & 2.9 \\
\hline
\end{tabular}

${ }^{a}$ Additive effect of QTL expressed in the trait unit. A negative value indicates that the resistance QTL allele was derived from SBCC145.

${ }^{\mathrm{b}}$ Proportion of phenotypic variation explained by each QTL 


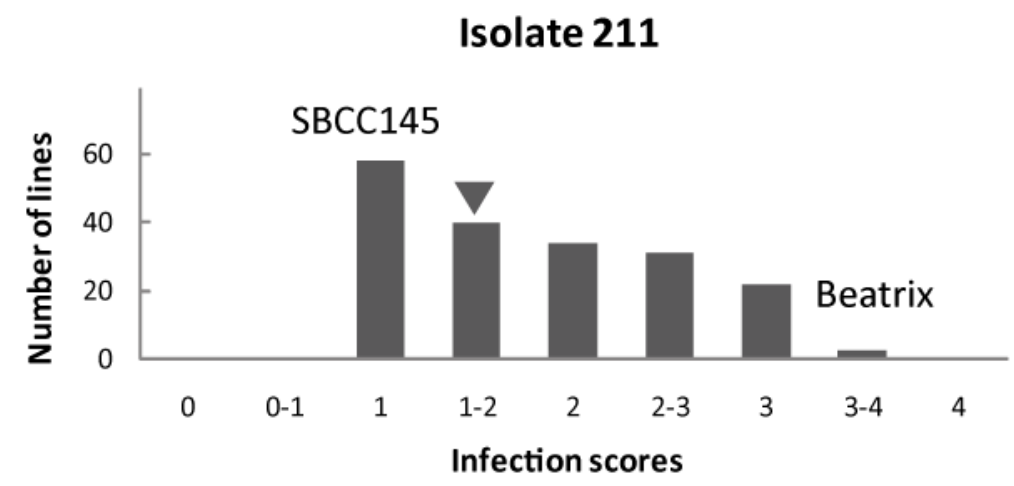

Isolate 224

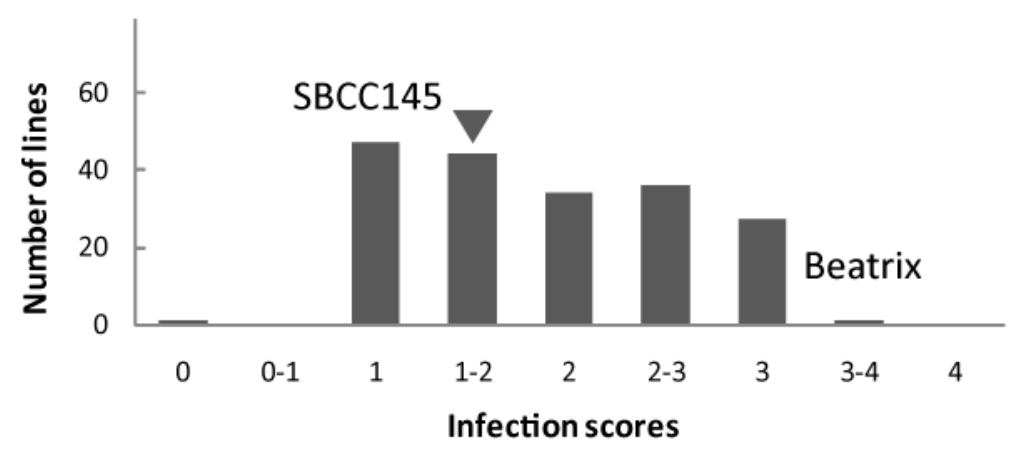

Figure 1. Frequency distribution of resistance/susceptibility to the different isolates of powdery mildew among the $184 \mathrm{DH}$ lines. Vertical arrows indicate a mean disease scores \pm SD of $1.81 \pm 0.72$ for isolate 211 and $1.87 \pm 0.72$ for isolate 224 . 

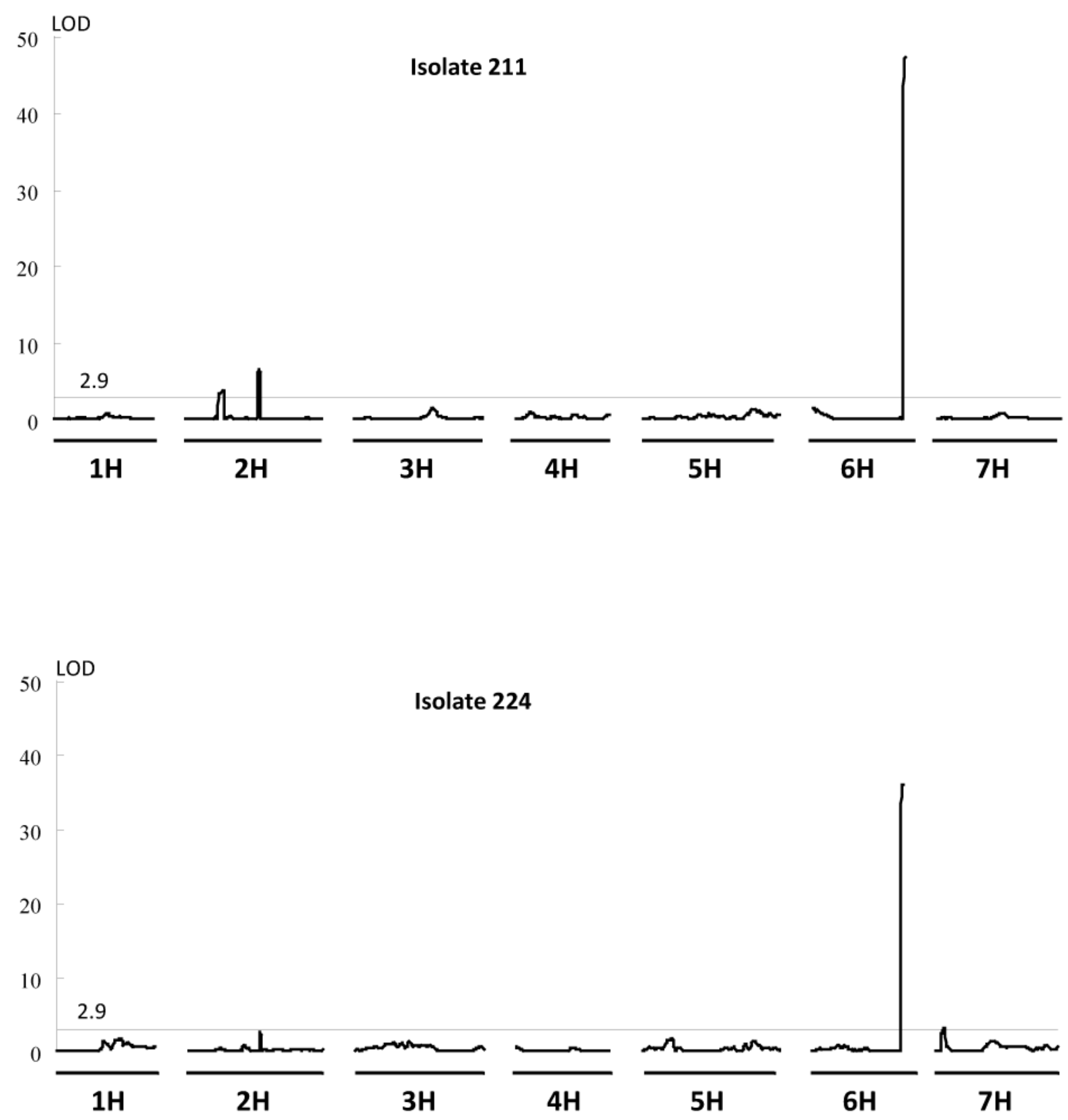

Figure 2. MQM LOD scans for resistance scores to two isolates of powdery mildew in $184 \mathrm{DH}$ lines. The horizontal dotted lines and the numbers above them indicate the significance threshold for QTL detection based on an experiment-wise error rate of less than 5\%, estimated with 1,000 permutations. 


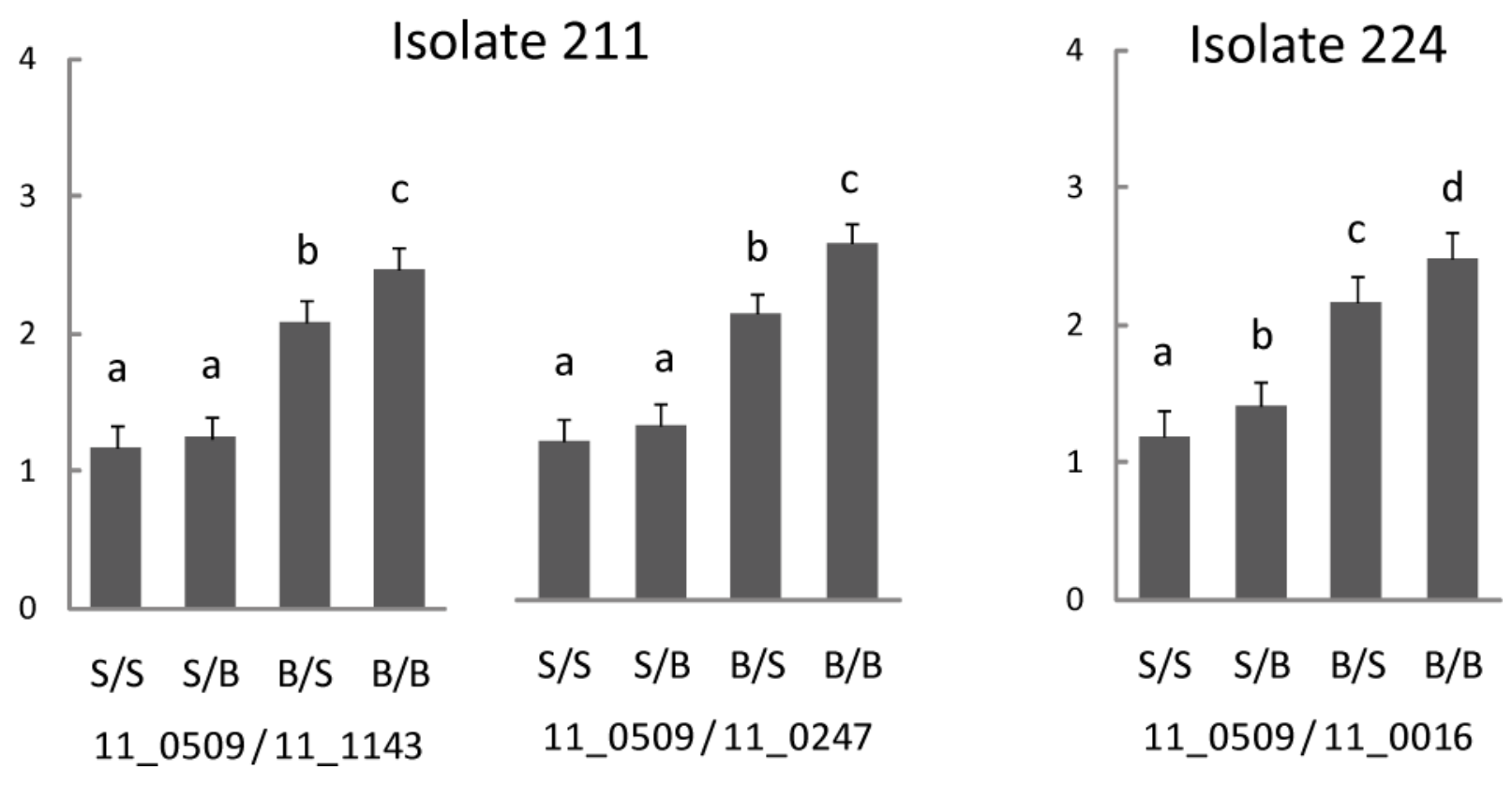

Figure 3. Mean disease scores of lines grouped according to the allele present at the closest marker to each QTL. $S$ represents the SBCC145 allele and $B$ the Beatrix allele. Error bars represent the LSD for $\mathrm{P}=0.05$. Different letters indicate significant differences at $\mathrm{P}<0.05$ 
Supplementary material:

Figure S1. SBCC145×Beatrix BOPA1 map

Figure S2. Segregation distortion for BOPA1 SNPs in the SBCC145×Beatrix population. Estimated positions of PpdH1, EBmac640 (closely linked to Eam6), vrs1, denso, VrnH2, VrnH1 and VrnH3 are depicted. Chi-square values are plotted in the lower part of the graph. 